\title{
Bronchopulmonary Dysplasia: Then, Now, and Next
}

\author{
Michael C. Tracy, MD and David N. Cornfield, MD
}

Bronchopulmonary dysplasia (BPD) has evolved considerably since its first description over 50 years ago. This review aims to provide a historical framework for conceptualizing BPD and a current understanding of the changing definition, epidemiology, pathophysiology, treatment, and outcomes of BPD. The transdisciplinary approach that led to the initial phenotypic description of BPD continues to hold promise today. Investigators are refining the definition of BPD in light of changes in clinical care and increasing survival rates of very preterm infants. Despite improvements in perinatal care the incidence of BPD continues to increase. There is growing recognition that antenatal risk factors play a key role in the development of BPD. Strategies designed to prevent or limit neonatal lung injury continue to evolve. Defining the phenotype of infants with BPD can meaningfully direct treatment. Infants with BPD benefit from an interdisciplinary approach to longitudinal care with a focus on growth and neurocognitive development. While the ultimate impact of BPD on long-term pulmonary morbidity remains an active area of investigation, current data indicate that most children and adolescents with a history of BPD have a quality of life comparable to that of other preterm infants.

Keywords: bronchopulmonary dysplasia, prematurity, airway malacia, pulmonary hypertension, oxygen, mechanical ventilation

\section{Introduction}

I 1967, NorThWAY ET AL. published a landmark article describing pulmonary disease in newborns after respiratory therapy for hyaline membrane disease (HMD) in the New England Journal of Medicine. ${ }^{1}$ They noted that this new disease was associated with mechanical ventilation and "high oxygen for longer than 150 hours $(6 \mathrm{~d})$." Notwithstanding immense improvements in care over the past 5 decades, the disease, named bronchopulmonary dysplasia (BPD), persists, with an incidence that is actually increasing. ${ }^{2}$ This article will provide an understanding of the initial description of BPD and highlight the evolving definition and pathophysiology of the disease. We will also review the current treatments and outcomes for infants with BPD.

\section{Historical Perspective: A New Disease Becomes an Old Disease}

The discovery of surfactant and the translation of this discovery to practice fueled the evolution of BPD. In 1957, John Clements identified a mucoprotein, later termed surfactant, which maintained alveolar stability in animal models. ${ }^{3}$ Avery and Mead, in a landmark article, demonstrated that the surface tension of lung extracts from premature infants with HMD was significantly higher compared with similarly sized infants dying of nonrespiratory causes. The finding led researchers to hypothesize that the increased surface tension and resultant lung collapse were due to the absence of a "surface-active material," or surfactant, in infants $<1,100 \mathrm{~g}$.

The death of President Kennedy's infant son from HMD intensified the national focus on neonatal lung disease. The impact of this news, the death of the only child born to a sitting president in the prior 100 years, catalyzed interest and investment in biomedical research in general and on HMD, specifically. HMD was estimated to account for $20 \%$ of all neonatal deaths in the late 1960 s-early 1970 s. $^{5}$

The term BPD was used to describe a new pattern of lung disease seen in premature infants who were surviving longer due to advances in ventilator care. In a carefully curated case study, Northway et al. described 32 premature infants with a history of severe respiratory distress syndrome (RDS), or HMD, who were treated with $>80 \%$ oxygen for at least $24 \mathrm{~h} .{ }^{1}$ Clinical, radiographic, and pathologic data were used to characterize the pattern of disease progression. Early disease began with a healing phase of RDS complicated by a component of oxygen toxicity. Researchers observed

Center for Excellence in Pulmonary Biology, Division of Pediatric Pulmonary, Asthma and Sleep Medicine, Department of Pediatrics, Stanford University School of Medicine, Stanford, California, USA. 
distinct pathologic changes in mucosal, alveolar, and vascular tissues. Histologic changes became more prominent with disease progression and included alternating hyperinflation and atelectasis, airway smooth muscle hyperplasia, airway epithelial injury, decreased alveolarization, and diffuse fibroproliferation.

A new intervention was needed, and surfactant therapy emerged as an era-defining therapy. ${ }^{6}$ In 1969, Liggins showed that lambs delivered prematurely after receiving intrafetal infusions of steroids had improved lung aeration, suggesting that surfactant production could be amplified by administration of prenatal steroids. ${ }^{7}$ Soon thereafter a trial demonstrated that prenatal steroids administered to infants $<32$ weeks gestation, $>24 \mathrm{~h}$ before delivery, decreased the incidence of neonatal $\mathrm{RDS}^{8}$

In addition to strategies designed to increase the endogenous production of surfactant, clinical trials of tracheal instillation of surfactant were initiated in the 1980s. Fujiwara et al. showed that early administration of surfactant to infants with HMD with a mean gestational age (GA) of 30 weeks improved oxygenation, lowered ventilatory requirements, and improved radiographic findings. 9 Throughout the 1980s there was a rapid expansion of clinical trials involving surfactant, which led to a dramatic reduction in mortality from neonatal respiratory distress. FDA approval for the first exogenous surfactant replacement therapy came in 1990, 33 years after Clements' seminal description.

The combination of prenatal maternal steroid treatment and exogenous postnatal surfactant therapy provided more benefit than either therapy alone and became the standard of care for infants with RDS. ${ }^{10,11}$ The focus shifted to minimizing damage from supplemental oxygen and assisted ventilation. Physicians developed new modes of ventilation, suggested lower oxygen saturation goals, and allowed for permissive hypercapnia to limit barotrauma. ${ }^{12}$

\section{Definition}

The definition of BPD evolved as treatments improved. Advances allowed for greater survival of infants born with lower birth weights and earlier GAs. In 1988, Shennan et al. noted that the Northway definition of BPD was not applicable to premature infants under 30 weeks GA. Use of supplemental oxygen at 36 weeks postmenstrual age (PMA) in infants with a birth weight of $<1,500 \mathrm{~g}$ could better predict abnormal pul- monary outcomes at 2 years of age. ${ }^{13}$ Pathology of neonatal lungs in the postsurfactant era revealed rare fibroproliferative changes, a cessation of acinar development with resultant fewer simplified alveoli, and less regional heterogeneity. ${ }^{14}$ Authors coined the term "new BPD" to describe this new pathophysiology arising from an arrest of lung development. ${ }^{15}$

The National Heart, Lung and Blood Institute (NHLBI) sponsored a workshop in 2000 that created a new consensus definition for BPD, which remains in wide use. ${ }^{16}$ This classification applies to infants with a GA $<32$ weeks who receive treatment with $>21 \%$ oxygen for at least 28 days. These infants are assessed at 36 weeks PMA, or discharge (whichever is first), and further divided into mild, moderate, or severe BPD based on the amount of oxygen and/or the use of positive pressure.

The NHLBI workshop definition of BPD poses several challenges, as outlined in a recent editorial. ${ }^{17}$ Foremost is that the definition uses treatment with oxygen to define the disease as opposed to more objective criteria. Furthermore, while BPD is associated with persistent pulmonary disease in early childhood, other clinical factors (including male sex, maternal smoking, intrauterine growth restriction, and race/ethnicity) may predict disease equally as well. ${ }^{18}$ Finally, the definition is quite broad, which limits the ability to study outcomes and apply new interventions. For example, an infant receiving low flow oxygen with an effective oxygen concentration of $30 \%$ and an infant with a tracheostomy on mechanical ventilation are both classified as severe BPD. As shown in Table 1, a growing number of publications propose more nuanced definitions of BPD, by distinguishing between the amount of supplemental oxygen and positive pressure required at 36 weeks PMA. ${ }^{19-21}$ Recent work suggests that we may be able to better predict pulmonary morbidity and neurocognitive outcomes by moving the time point for the diagnosis of BPD from 36 to 40 weeks PMA. ${ }^{22}$

\section{Epidemiology}

Despite the considerable increases in the survival rates of preterm infants, and a lower incidence of other morbidities, the incidence of BPD remains high. The National Institutes of Child Health and Disease (NICHD) Neonatal Research Network reported that between 1993 and 2012 in infants ranging of GA between 22 and 28 weeks, the incidence of BPD ranged between $32 \%$ and 45\%. ${ }^{2}$ From 2009 through

Table 1. Evolving Criteria for Bronchopulmonary Dysplasia Definitions

\begin{tabular}{|c|c|c|c|c|c|c|}
\hline \multirow{2}{*}{$\begin{array}{l}\text { Criteria used to define } \\
B P D \text { severity }\end{array}$} & \multicolumn{2}{|c|}{$P M A$} & \multicolumn{2}{|c|}{ Oxygen } & \multicolumn{2}{|r|}{ Flow } \\
\hline & 36 weeks & 40 weeks & $\geq 28$ days & $\% \mathrm{FiO}_{2}$ & Low vs. High flow & Noninvasive vs. Invasive \\
\hline NHLBI, $2000^{16}$ & $\mathrm{X}$ & & $\mathrm{X}$ & $\mathrm{X}$ & & \\
\hline Isayama et al., $2017^{22}$ & & $\mathrm{x}$ & & & $\mathrm{x}$ & \\
\hline Abman et al., $2017^{19}$ & $\mathrm{X}$ & & $\mathrm{x}$ & $\mathrm{x}$ & & $\mathrm{x}$ \\
\hline NICHD, $2018^{20}$ & $\mathrm{x}$ & & & $\mathrm{x}$ & $\mathrm{X}$ & $\mathrm{X}$ \\
\hline Jensen et al., $2019^{21}$ & $\mathrm{X}$ & & & & $\mathrm{x}$ & $\mathrm{x}$ \\
\hline
\end{tabular}

Definitions of BPD generally include 3 major components: PMA, oxygen, and flow. Comparing 5 contemporary definitions of BPD, we can see trends emerge over time. Most definitions use 36 weeks PMA as the time point of assessment. Earlier definitions use $\geq 28$ days of oxygen and the $\% \mathrm{FiO}_{2}$ as criteria to define BPD severity. In contrast, Isayama and Jensen determined optimal definitions by amount of flow, rather than oxygen. While the NHLBI 2000 Workshop definition considered flow in severity criteria, more recent definitions define low versus high flow and noninvasive versus invasive support in severity definitions.

$\mathrm{BPD}$, bronchopulmonary dysplasia; $\% \mathrm{FiO}_{2}$, fraction of inspired oxygen; NHLBI, National Heart, Lung and Blood Institute; NICHD, National Institutes of Child Health and Disease; PMA, postmenstrual age. 
2012 the incidence of BPD in infants 26-27 weeks GA increased. This is likely in context of improved survival of extremely preterm infants. Rates of BPD in the Vermont Oxford Network database from 2005 to 2014 showed a small decrease, from $32 \%$ to $29 \%{ }^{23}$

The NHLBI definition of BPD yields an incidence of severe $\mathrm{BPD}$ of $16 \%$ in premature infants $<32$ weeks and with a birth weight $<1,000$ g. ${ }^{24}$ Using this estimate authors have postulated that $\sim 13,000$ patients are diagnosed with severe BPD each year in the United States, with $\sim 2,000$ infants and children with severe BPD on mechanical ventilation. ${ }^{19}$

\section{Pathophysiology}

\section{Antenatal factors associated with development of BPD}

While postnatal stressors contribute to the development of $\mathrm{BPD}$, a growing body of literature underscores the importance of prenatal insults as a determinate of both neonatal pulmonary vascular disease and inflammation. ${ }^{25-27}$ Maternal smoking and maternal hypertensive disorders in the antenatal period are associated with increased odds of BPD in infants. ${ }^{25} \mathrm{~A}$ prospective cohort study of preterm infants showed a strong association between exposure to maternal preeclampsia and the development of BPD. ${ }^{28}$ The biological basis for this finding is likely an alteration in fetal angiogenesis. Preeclampsia is associated with increased circulating levels of soluble vascular endothelial growth factor receptor-1 (soluble VEGFR1, or sFlt1). ${ }^{29}$ In animal models, elevated levels of sFlt-1 in amniotic fluid reduce alveolarization and pulmonary vascular growth during infancy. ${ }^{30} \mathrm{~A}$ retrospective cohort study of premature infants with moderate and severe BPD revealed that low birth weight for GA, a common manifestation of placental insufficiency, was associated with increased risk for pulmonary hypertension $(\mathrm{PH})$ at 36 weeks. ${ }^{31}$ An examination of placental histopathology further buttressed this association. Pathology of the maternal vasculature of the placenta, defined as maternal vascular underperfusion (MVU), was found to be associated with the development of BPD. ${ }^{32} \mathrm{MVU}$ is associated with maternal hypertension and, thus, fetal growth restriction as well, supporting the idea that fetal hypoxia and ischemia have a role in pulmonary vascular development.

Chorioamnionitis is common in preterm labor, and some sources suggest that this is an antenatal risk factor for BPD. Research on the association between chorioamnionitis and BPD outcomes is complicated by multiple confounding variables, including the routine use of antenatal steroids, leading some authors to suggest that it may not be a strong risk factor. ${ }^{33}$

Ongoing "-omic" approaches to identify antenatal factors that influence vascular growth and inflammation hold promise. ${ }^{34}$ Genomic studies in BPD continue to work to identify heritable factors, with some studies arguing against the importance of heritable factors, although others argue that ongoing work will likely reveal important candidate genes. ${ }^{35-37}$ Research on the maternal and neonatal microbiome holds promise, with a growing number of studies describing changes in the airway microbiome in infants with BPD. ${ }^{38}$

\section{Prevention}

The optimal approach for decreasing the incidence of BPD is preventing premature birth. When this is not pos- sible, it is important to minimize lung injury. ${ }^{39}$ The early application of nasal continuous positive airway pressure decreases the need for surfactant and mechanical ventilation and decreases overall BPD incidence. ${ }^{40,41}$ For infants requiring mechanical ventilation, the use of surfactant within $2 \mathrm{~h}$ of age appears to reduce the risk for BPD. ${ }^{42}$ For infants who receive surfactant, there are several methods for administration, and less invasive surfactant administration may hold the most promise. ${ }^{39}$ Infants requiring mechanical ventilation may be best managed with a volume-targeted, rather than pressure-targeted, ventilator strategy to prevent BPD. $^{43}$

Currently, there are no therapies available that reliably prevent BPD. Of the medications to prevent BPD, vitamin A, caffeine, and corticosteroids have the most supporting evidence. Vitamin A is at low levels in preterm infants and is essential for lung development. Intramuscular vitamin A appears to decrease the risk of death or chronic lung disease. ${ }^{44}$ Caffeine reduces apnea of prematurity and increases respiratory drive, while also improving diaphragmatic contractility and lung compliance. Early caffeine use is associated with a decreased incidence of BPD, perhaps owing to its antifibrotic properties. ${ }^{45,46}$

While antenatal corticosteroids have not been shown to decrease the risk of BPD, postnatal steroids may improve lung function, weaning from the ventilator, and the incidence of BPD. Research on timing (early or late), route (inhaled vs. systemic), dosage, and duration of steroids is ongoing. ${ }^{47,48}$ Early dexamethasone use in premature infants may decrease BPD incidence, but may increase the incidence of cerebral palsy. ${ }^{49}$ Low dose hydrocortisone in the first 10 days of life for infants $<28$ weeks PMA may increase survival without BPD. ${ }^{50}$ Use of corticosteroids, after 7 days of age, in ventilatordependent infants, may reduce mortality without compromising long-term neurodevelopmental outcome. ${ }^{51,52}$

Several emerging therapies for the prevention of BPD hold promise. In rodent models of BPD, use of mesenchymal stromal cells (MSCs), or the conditioned media (CM) from MSC, mitigated neonatal hyperoxia-induced lung injury. ${ }^{53,54}$ Interestingly, in both studies the beneficial effects, preserved angiogenesis and alveolarization, of CM were greater than MSCs alone. Further work has demonstrated that beneficial effects of MSCs do not derive from engraftment, but rather from paracrine effects. ${ }^{55,56}$ Phase 1 trials of intratracheal administration of MSCs in very preterm infants have demonstrated safety and feasibility. ${ }^{57,58}$ The efficacy of CM from MSCs suggested that the secretome of MSCs might possess therapeutic potential. Recent studies provide strong evidence that exosomes produced by MSC derived from either human bone marrow or umbilical vessels preserve lung structure and function in hyperoxia-induced lung injury in mice. ${ }^{59}$ Thus, exosomes which range from 20 to $100 \mathrm{~nm}$ in size and can deliver cargo to other cells represent a remarkably attractive nanotherapy for BPD. ${ }^{60}$ Additional potential therapies include the use of nanoparticles to deliver proangiogenic transcription factors (FOXM1 or FOXF1) into the pulmonary vasculature. Application of this therapy in a mouse model of BPD improved angiogenesis and alveolarization. ${ }^{61}$ Finally, insulin-like growth factor-1 (IGF-1) plays an important developmental role in the fetus and is decreased in premature infants. A phase 2 clinical trial of IGF-1 therapy for retinopathy of prematurity showed a decreased incidence of severe BPD. ${ }^{62}$ 


\section{Established BPD: Understanding phenotypes}

The broad spectrum of disease in infants with BPD highlights the continued importance of narrow phenotyping. One approach, as illustrated in Fig. 1, is to phenotype infants with BPD by considering 3 primary components: airway, parenchymal, and vascular disease. ${ }^{63,64}$

\section{Airway}

Airway pathophysiology can be divided into 2 components: large and small airways. Large airway malacia, such as tracheomalacia or bronchomalacia, is associated with morbidity in infants with BPD. ${ }^{65}$ Premature infants with BPD may be at increased risk for developing tracheobronchomalacia given the increased compliance of neonatal airways, use of positive pressure ventilation, and obstructive respiratory physiology. ${ }^{66}$ Flexible bronchoscopy is one diagnostic tool for evaluating airway pathology and is well tolerated in infants with severe BPD. ${ }^{67} \mathrm{~A}$ retrospective cohort study of 974 infants with BPD who underwent bronchoscopy identified an incidence of tracheobronchomalacia of $36.2 \%$ and an increased likelihood of pneumonia, gastroesophageal reflux, tracheostomy, and gastrostomy. ${ }^{65}$

Infant pulmonary function testing (iPFT) demonstrates that the majority of infants with severe BPD have obstructive respiratory physiology. A prospective cohort study of 110 infants with severe BPD and assessed by iPFT demonstrated that $91 \%$ of infants had an obstructive physiology. ${ }^{68}$ Furthermore, airflow improved in $66 \%$ of the infants with bronchodilator treatment. However, in a subset of infants with BPD, airflow obstruction does not improve with bronchodilator therapy. ${ }^{69}$ Airflow obstruction can persist into childhood and adulthood, with young adults who demonstrate increased bronchial responsiveness. ${ }^{70-72}$ Longitudinal data on airflow obstruction in very low birth weight infants from last decade of the 20th and first decade of the 21st century demonstrate no change in the incidence of airflow obstruction at age 8 . The persistence of significant obstructive lung disease in this population despite decreased use of mechanical ventilation suggests that prematurity, irrespective of the therapy, represents a significant risk factor for obstructive lung disease. ${ }^{73}$

\section{Parenchymal}

Alveolar number is decreased, and alveolar size is increased in infants with BPD. This observation, which is the result of decreased angiogenesis, informs the collective understanding of parenchymal lung disease in the postsurfactant era. ${ }^{74}$ Additional pro-inflammatory insults to the lung parenchyma such as oxygen toxicity, infection, and pulmonary aspiration further compromise lung growth. Decreased pulmonary vasculature and lung surface area impair gas exchange. Moreover, hypoxic pulmonary vasoconstriction, which increases ventilation and perfusion matching, may also be compromised, resulting in more intrapulmonary shunting and hypoxia. ${ }^{75}$

Pulmonary function testing and lung imaging can define parenchymal disease. iPFT in infants and toddlers with BPD demonstrates decreases in both pulmonary capillary blood volume and membrane diffusing capacity. ${ }^{76}$ However, both components increase with somatic growth. This supports the understanding of BPD alveolar pathophysiology as a reduced number of simplified alveoli with a diminished pulmonary capillary bed that can increase over time. Magnetic resonance imaging (MRI) modalities, using hyperpolarized helium-3, contribute to the understanding of continued alveolarization over time, revealing similar alveolar size in both preterm and term school age children. ${ }^{77}$

Chest imaging of infants with BPD can include a variety of approaches: chest radiographs, computed tomography (CT), and MRI. Scoring systems for CT of the chest exist to define clinical phenotypes and predict short- and long-term prognosis. ${ }^{78,79}$ Given concerns for ionizing radiation, pulmonary MRI holds promise, with the ability to apply similar scoring systems to quantify parenchymal disease. ${ }^{80}$

\section{Vascular}

Increased pulmonary vascular tone or $\mathrm{PH}$ is a key component of the clinical phenotype of many infants with BPD. PH is associated with both increased morbidity and mortality in infants and children with BPD. ${ }^{81,82}$ The underlying pathophysiology of the pulmonary vasculature includes smooth muscle cell hyperplasia, increased vascular tone, and decreased angiogenesis. $^{83}$ These structural and functional changes lead to increased pulmonary vascular resistance.
FIG. 1. A phenotypic approach to patients with established BPD. Characterizing the phenotype of infants with established BPD can be done using 3 primary components: parenchymal, airway, and vascular disease. ${ }^{63,64}$ Anatomic images are public domain. BPD, bronchopulmonary dysplasia.

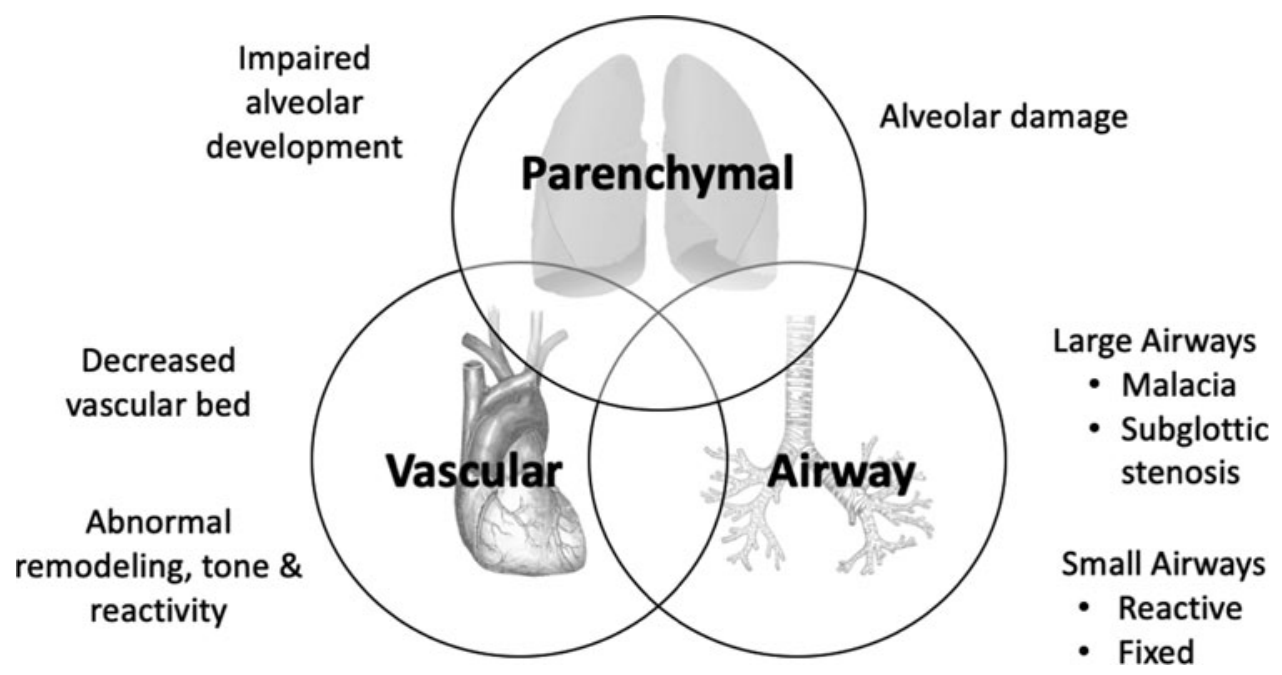


Recently published guidelines from the Pediatric Pulmonary Hypertension Network (PPHNet) for infants and children with BPD and PH call for screening echocardiograms in infants with moderate-to-severe BPD at the time of diagnosis at 36 weeks. ${ }^{84}$ Infants with moderate-to-severe BPD are at a higher risk for $\mathrm{PH}$, with an incidence of $16 \%-$ $25 \%$. However, even infants with mild BPD may develop $\mathrm{PH}^{85}$ Echocardiographic evaluation, at day of life 7 , in infants on ventilator support, has significant prognostic implications, as abnormal cardiac septal movement is associated with $\mathrm{PH}$ at 36 weeks. ${ }^{86}$ Evaluation for vascular comorbidities, such as pulmonary arterial and venous stenosis, is essential and may be completed with CT angiography. For infants with severe or persistent $\mathrm{PH}$, cardiac catheterization is indicated for the confirmation of the diagnosis and the assessment of pulmonary vascular reactivity. Biomarkers, such as serial brain natriuretic peptide (BNP) and N-terminal-probrain natriuretic peptide (NTproBNP), are increasingly being used in addition to traditional diagnostic tools to guide therapy. ${ }^{87,88}$

\section{Treatment of Established BPD}

As is the case with many pediatric diseases, empirical data relative to management of BPD are limited. Recently, the BPD Collaborative published recommendations for an interdisciplinary approach to the longitudinal management of infants with severe BPD. ${ }^{19}$ The transition from strategies to prevent BPD to the chronic management of BPD is a key focus of the recommendations. Chronic care principles include optimizing ventilation and oxygenation, promoting growth, screening for long term sequelae, and assessing neurodevelopmental outcomes. Table 2 outlines the diagnostic evaluation and treatment options for infants with BPD. An interdisciplinary care team should be composed of subspecialty physicians, including neonatologists, pediatric intensivists, pulmonologists, cardiologists, otolaryngologists, surgeons, and radiologists. These providers must work in concert with nurses, advanced practice providers, respiratory therapists, occupational, speech, and physical therapists, social workers, and dietitians to optimize care of these infants.

\section{Ventilation}

Strategies for ventilation of established BPD differ substantially from those for preventing BPD. ${ }^{19,89,90}$ Specifically, providers must recognize the divergent physiology between a young preterm infant with compliant lungs, normal airway resistance, and homogeneous parenchyma and an infant with established BPD with high airway resistance, poor lung compliance, and heterogenous parenchymal disease with areas of air trapping. Infants with severe BPD and dependence on mechanical ventilation after 36 weeks generally benefit from larger tidal volumes, up to $10-12 \mathrm{~mL} / \mathrm{kg}$, rather than the $3-5 \mathrm{~mL} / \mathrm{kg}$ for younger infants earlier in their neonatal course. Longer inspiratory times, $>0.6 \mathrm{~s}$, are needed to assure recruitment and adequate gas exchange of heterogenous alveolar units that fill and empty slowly. Importantly, longer inspiratory times require slower rates to allow exhalation and mitigate further air trapping. There is increasing appreciation of the importance of optimal positive endexpiratory pressure (PEEP) levels in this population. In addition to standard indications in infants with atelectasis, pulmonary edema, large airway malacia, and abdominal competition, infants with severe BPD may benefit from a higher PEEP to address small airway collapse and subsequent air-trapping with patient/ventilator synchrony. ${ }^{91}$ There are a number of approaches to determine the optimal PEEP setting. These include assessing the airway diameter with

Table 2. Diagnostic and Treatment Approaches for Established Bronchopulmonary Dysplasia Based on Disease Phenotype

\begin{tabular}{|c|c|c|}
\hline Disease phenotype & Diagnostic evaluation & Treatment \\
\hline Parenchymal & $\begin{array}{l}\text { Oximetry } \\
\text { Lung imaging } \\
\text { - Chest radiograph } \\
\text { - CT chest } \\
\text { - MRI chest } \\
\text { Blood gas, serum bicarbonate } \\
\text { Evaluate aspiration } \\
\text { - VFSS, FEES } \\
\text { Respiratory viral and bacterial studies }\end{array}$ & $\begin{array}{l}\text { Oxygen } \\
\text { Diuretics } \\
\text { Chronic ventilation } \\
\text { - Noninvasive } \\
\text { - Invasive } \\
\text { (+/- tracheostomy) } \\
\text { Safe feeding route } \\
\text { Management of GERD } \\
\text { Antibiotic therapy } \\
\text { Palivizumab and vaccines }\end{array}$ \\
\hline $\begin{array}{l}\text { Airway } \\
\text { - Large airways } \\
\text { - Small airways }\end{array}$ & $\begin{array}{l}\text { Bronchoscopy } \\
\text { - Flexible } \\
\text { - Rigid } \\
\text { iPFTs }\end{array}$ & $\begin{array}{l}\text { Chronic ventilation } \\
\text { - Optimize PEEP } \\
\text { Surgical intervention } \\
\text { Bronchodilators } \\
\text { Steroids } \\
\text { - Systemic and Inhaled }\end{array}$ \\
\hline Vascular & $\begin{array}{l}\text { Echocardiogram } \\
\text { Biomarkers (BNP, NT-proBNP) } \\
\text { CTA } \\
\text { Cardiac catheterization }\end{array}$ & $\begin{array}{l}\text { Optimize parenchymal and airway } \\
\text { management } \\
\text { Vasodilator therapy }\end{array}$ \\
\hline
\end{tabular}

BNP, brain natriuretic peptide; CT, computed tomography; CTA, computed tomography angiography; FEES, fiberoptic endoscopic evaluation of swallowing; GERD, gastroesophageal reflux; iPFT, infant pulmonary function testing; MRI, magnetic resonance imaging; NT-proBNP, N-terminal-probrain natriuretic peptide; PEEP, positive end-expiratory pressure; VFSS, videofluoroscopic swallowing study. 
bronchoscopy, analyzing ventilator flow-volume loops and scalar tracings for evidence of expiratory flow limitation, and performing esophageal pressure monitoring.

Although clinical trials in support of this ventilator strategy are lacking, careful consideration of the patient physiology can guide the clinician in determining the optimal strategy. Strategies for long-term weaning from mechanical ventilation are not standardized, but generally focus on very gradual changes that still permit clinical stability, growth, and decreasing exposure to sedative agents. ${ }^{92}$ Home ventilator options continue to expand, with longer battery life and improved user interfaces that ease the transition to a long-term facility or the home setting. ${ }^{90}$

\section{Tracheostomy}

For an infant with severe BPD whether and when to place a tracheostomy for chronic ventilatory support is a complicated decision. Considerations include appropriate patient selection, timing of placement, long-term outcomes, and disposition options outside of the acute care setting.

With regard to long term outcomes, a single center retrospective review of infants with severe BPD who were dependent on tracheostomy and mechanical ventilation at home found that of 102 infants, just over $80 \%$ survived, and the majority $(67.6 \%)$ was liberated from mechanical ventilation before age 5 , with a median age of 2 years. ${ }^{93} \mathrm{~A}$ similar percentage of patients were decannulated $(58.8 \%)$, with median age of decannulation of 37.5 months.

Infants with severe BPD who are tracheostomy and ventilator dependent are at high risk for long-term neurodevelopmental impairments. ${ }^{94,95}$ Infants with BPD and earlier tracheostomy placement may have better neurodevelopmental outcomes. ${ }^{94}$ Tracheostomy placement may allow decreased sedation requirements, improved growth, and participation in developmental therapy sessions. ${ }^{96}$ If a decision is made to place a tracheostomy and commit to longterm mechanical ventilation, care coordination, discharge planning, parental engagement, and involvement of an interdisciplinary team of providers may improve survival and decrease hospital length of stay. ${ }^{97,98}$

\section{Oxygen}

Early research in the postsurfactant era of BPD suggested that chronic oxygen therapy may enhance growth and improve sleep duration, while decreasing arousals. ${ }^{99,100}$ In addition, oxygen causes acute pulmonary vasodilation and prevents chronic hypoxia that can lead to pulmonary vasoconstriction. ${ }^{84,101}$ In this context, a slow weaning strategy of oxygen flow rate, with attention to oxygen saturation, growth, and clinical examination, is the established practice for many physicians. ${ }^{102,103}$ Methods for monitoring oxygen saturation include pulse oximetry in the home or clinic setting and overnight polysomnography. ${ }^{102-104}$ Goals for oxygen saturation rely on expert opinion and differ in published guidelines. The American Thoracic Society clinical practice guideline for home oxygen therapy recommends oxygen therapy for saturation less than or equal to $93 \%$, while the European Respiratory Society guideline for long-term management of BPD recommends a minimum saturation target of $90 \% .^{103,105}$ For infants with BPD and PH, PPHNet recommends goal oxygen saturations between $92 \%$ and $95 \% .^{84}$
While some authors argue that the availability of home oxygen may decrease hospital length of stay, others suggest that it is associated with increased health care use. ${ }^{105,106}$ The average duration of oxygen therapy is center specific with factors such as home altitude playing an important role. One single center study reported the median duration of oxygen therapy as 10.1 months after initial hospital discharge. ${ }^{104}$

\section{Nutrition}

Optimizing growth with adequate nutrition is a key component for the management of BPD, not only for lung development but also for long-term neurodevelopmental outcomes. $^{107,108}$ While weight gain is often the focus, linear growth may be a better measure for organ development; however, in clinical practice this is challenging to accurately record. ${ }^{19}$ Caloric intake may need to be increased to achieve adequate linear growth. Infants with BPD require in the range of $130-150 \mathrm{kcal} / \mathrm{kg} / \mathrm{day}$ by caloric fortification of breast milk or use of formula. ${ }^{19,108}$ With regard to fluid volumes, for infants with established BPD, there is no compelling evidence for fluid restriction. ${ }^{109}$ Regular measurements of weight and length are essential, as growth goals change over the first year of life, and decreased growth velocity may alert providers to other long-term sequelae of BPD.

\section{Aspiration/feeding route}

Dysphagia with chronic pulmonary aspiration of oral feeds or gastric reflux is a significant comorbidity for many infants and children with BPD. Dysfunctional swallow mechanics are often secondary to delayed maturation of coordination of oropharyngeal and respiratory mechanics in infants requiring mechanical ventilation or tube feeding. Feeding difficulties may be further complicated by neurologic insults and/or airway anomalies. Gastrostomy tube placement is a common intervention for infants with severe BPD and is associated with a higher risk for poor growth and neurodevelopmental impairment. ${ }^{110}$

Diagnosing dysphagia is a challenge, with poor sensitivity and specificity of current diagnostic testing modalities. ${ }^{111}$ Management of gastroesophageal reflux in this population is also limited by challenges with diagnostic testing and relies on clinical findings, with conservative measures to control reflux favored over pharmacologic approaches. ${ }^{112}$ Given these limitations, several centers initiate prophylactic postpyloric feeding or Nissen fundoplication in infants with severe BPD to minimize the likelihood of aspiration. ${ }^{98}$ Recent work suggests that early use of transpyloric feeding is associated with reduced risk of death or BPD. ${ }^{113}$ However for infants with established BPD, transpyloric feeding in comparison to gastric feeding may not be of benefit and rather may carry increased risks. ${ }^{114}$ When antireflux surgery with fundoplication is performed, it may decrease oxygen requirement in a subset of infants. 115

\section{Pharmacotherapy}

Definitive literature on the efficacy of specific medications is lacking in established BPD. There is considerable variability in practice between centers. A point prevalence study of 8 neonatal intensive care units in 2013 highlighted significant differences in the use of diuretics, inhaled bronchodilators, and inhaled corticosteroids. ${ }^{116}$ 


\section{Diuretics}

Diuretics are commonly prescribed in premature infants with BPD to decrease interstitial pulmonary edema. Older literature shows that the use of diuretics in infants with BPD acutely improves lung compliance and airway resistance and chronically may improve compliance and oxygenation. ${ }^{11-119}$ However, there is no evidence of long-term benefit from early diuretic exposure in preterm infants or for decreasing the duration of either supplemental oxygen support or mechanical ventilation. ${ }^{120}$ In a retrospective cohort study of 35 hospitals and 1,429 infants with BPD between 2007 and 2011, 86\% of infants received diuretic therapy, with a median duration of 9 days, although with marked interinstitutional differences in the duration of therapy. ${ }^{121}$

Furosemide is the most prescribed diuretic in infants with BPD, although thiazide diuretics (chlorothiazide and hydrochlorothiazide) and spironolactone are also widely used, both in combination or as single therapy. ${ }^{121}$ Diuretics must be used with caution because of their potential complications, including electrolyte abnormalities. Calcium excretion from furosemide may increase the risk for metabolic bone disease and nephrocalcinosis. ${ }^{121,122}$ The optimal practice for weaning diuretics is yet to be defined. In the outpatient setting, one common approach is weaning by allowing the infant to "outgrow" the medication by not increasing the dose as the infant gains weight. ${ }^{105}$ There is a lack of consensus on how to balance weaning oxygen versus diuretics in the outpatient setting, with regional differences in approach. $^{102}$

\section{Bronchodilators}

Bronchodilator therapy is commonly used in infants with BPD in both the inpatient and outpatient setting, with notable variability in prescription patterns. ${ }^{123}$ While some infants with BPD may have short term benefit from therapy, careful evaluation of response is essential as infants with comorbid large airway malacia may worsen with bronchodilator therapy. ${ }^{68,71,72}$ Data on use of $\beta$-agonists (albuterol) or anticholinergic medications (ipratropium bromide) for the chronic management of children with BPD are incomplete. ${ }^{124,125}$ Guidelines suggest considering bronchodilator therapy for the subgroup of infants with BPD and an asthma-like phenotype. ${ }^{105}$

\section{Steroids}

The majority of literature on postnatal corticosteroids is focused on the neonatal period before the diagnosis of BPD. Inhaled and systemic corticosteroids are used commonly for infants with established BPD, with notable variability in the use of inhaled corticosteroids between centers. ${ }^{116}$ Possible benefits for corticosteroids in this population include decreasing inflammation and airway edema, decreasing lung fibrosis, and supporting surfactant production. ${ }^{19}$ This must be balanced with the risks of adverse effects, which can include adrenal suppression, growth limitation, hypertension, and neurocognitive impairment. ${ }^{126}$ Given the risks and the lack of data on the use of inhaled or systemic steroids in children with BPD, reserving a trial of corticosteroid therapy for the subgroup of infants with severe BPD who have an inflammatory phenotype is prudent. ${ }^{63,105,127}$

\section{Palivizumab}

Given the high risk of hospitalization from respiratory syncytial virus (RSV) in preterm infants with BPD, the American Academy of Pediatrics recommends RSV prophylaxis with Palivizumab, a humanized monoclonal antibody against the RSV F glycoprotein. ${ }^{128}$ The costs of palivizumab are significant, and obtaining insurance approval can be a challenge. A recent analysis found that palivizumab prophylaxis for RSV is cost-effective in preterm infants, including those with BPD. ${ }^{129}$

\section{PH therapy}

The treatment of PH in infants with BPD begins with the management of airway and parenchymal disease. Following this, PH-targeted therapy should be considered acutely in context of a $\mathrm{PH}$ crisis or in the presence of sustained $\mathrm{PH}^{84}$ Before initiating pulmonary vasodilator therapy it is important to make sure that increased pulmonary vascular resistance is not secondary to a fixed vascular obstruction, such as left-sided heart disease or pulmonary vein stenosis. Use of vasodilators in context of a fixed obstruction can lead to pulmonary edema and clinical decompensation.

With regard to specific agents, inhaled nitric oxide (iNO) is indicated for treatment of acute $\mathrm{PH}$ crises in infants with BPD, given its benefit in selectively dilating pulmonary vasculature and improving ventilation-perfusion matching and oxygenation. ${ }^{84,130}$ For pharmacotherapy of sustained PH, sildenafil, a phosphodiesterase inhibitor, is the most commonly used agent. Sildenafil use in preterm infants has increased dramatically since the early 2000s, although it remains low overall. ${ }^{131}$ Research on sildenafil in children with BPD and PH is limited, but the available data are promising relative to both efficacy and safety. A retrospective study of 25 children $<2$ years of age with BPD and PH on chronic sildenafil therapy found that in $88 \%$ of children hemodynamic parameters improved. Moreover, the majority of infants on iNO were able to wean off with the addition of sildenafil. Adverse events were limited. ${ }^{132}$ When $\mathrm{PH}$ therapy is initiated, close monitoring by a multidisciplinary $\mathrm{PH}$ team is essential, particularly when modifying therapy and transitioning from inpatient to outpatient care. ${ }^{84}$

\section{Outcomes}

Children with BPD in the postsurfactant era are at increased risk for both short- and long-term pulmonary morbidity. ${ }^{133}$ In the short term, BPD is associated with respiratory disease at 1 year of age, including the increased risk for rehospitalization. ${ }^{18,134}$ In the long term there is increasing evidence of persistent abnormalities in lung function and structure in former preterm infants as they progress through childhood and adulthood. ${ }^{70,135}$ This being said, most children with a history of BPD appear to have similar quality of life and functional status to other preterm infants without BPD. ${ }^{136}$ Given the risks of respiratory morbidity, and possible link to the development of chronic obstructive pulmonary disease, focus must remain on limiting exposure to infections and environmental toxins, while continuing longterm follow-up. ${ }^{137,138}$ 


\section{Conclusion}

The definition of BPD continues to evolve. The identification of antenatal risk factors for BPD will potentially allow for earlier therapies for the prevention of BPD. Strategies to treat infants with BPD will improve by wedding new omic approaches with increasingly detailed disease phenotypes. Long term studies are needed to inform our collective understanding of the natural history of this disease.

\section{Author Disclosure Statement}

No competing financial interests exist.

\section{Funding Information}

No funding was received.

\section{References}

1. Northway Jr. WH, Rosan RC, Porter DY. Pulmonary disease following respirator therapy of hyaline-membrane disease: bronchopulmonary dysplasia. N Engl J Med 1967; 276:357-368.

2. Stoll BJ, Hansen NI, Bell EF, et al. Trends in care practices, morbidity, and mortality of extremely preterm neonates, 1993-2012. JAMA 2015; 314:1039-1051.

3. Clements JA. Surface tension of lung extracts. Proc Soc Exp Biol Med 1957; 95:170-172.

4. Avery ME, Mead J. Surface properties in relation to atelectasis and hyaline membrane disease. AMA J Dis Child 1959; 97:517-523.

5. Farrell PM, Wood RE. Epidemiology of hyaline membrane disease in the United States: analysis of national mortality statistics. Pediatrics 1976; 58:167-176.

6. Clements JA, Avery ME. Lung surfactant and neonatal respiratory distress syndrome. Am J Respir Crit Care Med 1998; 157:S59-S66.

7. Liggins GC. Premature delivery of foetal lambs infused with glucocorticoids. J Endocrinol 1969; 45:515-523.

8. Liggins GC, Howie RN. A controlled trial of antepartum glucocorticoid treatment for prevention of the respiratory distress syndrome in premature infants. Pediatrics 1972; 50:515-525.

9. Fujiwara T, Chida S, Watabe Y, et al. Artificial surfactant therapy in hyaline-membrane disease. Lancet 1980; 315: $55-59$.

10. Jobe AH, Mitchell BR, Gunkel JH. Beneficial effects of the combined use of prenatal corticosteroids and postnatal surfactant on preterm infants. Am J Obstet Gynecol 1993; 168:508-513.

11. Kari MA, Eronen M, Virtanen M, et al. Prenatal dexamethasone treatment in conjunction with rescue therapy of human surfactant: a randomized placebo-controlled multicenter study. Pediatrics 1994; 93:730-736.

12. O'Brodovich HM, Mellins RB. Bronchopulmonary dysplasia: unresolved neonatal acute lung injury. Am Rev Respir Dis 1985; 132:694-709.

13. Shennan AT, Dunn MS, Ohlsson A, et al. Abnormal pulmonary outcomes in premature infants: prediction from oxygen requirement in the neonatal period. Pediatrics 1988; 82:527-532.

14. Husain AN, Siddiqui NH, Stocker JT. Pathology of arrested acinar development in postsurfactant bronchopulmonary dysplasia. Hum Pathol 1998; 29:710-717.

15. Jobe AJ. The new BPD: an arrest of lung development. Pediatr Res 1999; 46:641.
16. Jobe $\mathrm{AH}$, Bancalari E. Bronchopulmonary dysplasia. Am J Respir Crit Care Med 2001; 163:1723-1729.

17. Jobe AH, Steinhorn R. Can we define bronchopulmonary dysplasia? J Pediatr 2017; 188:19-23.

18. Keller RL, Feng R, DeMauro SB, et al. Bronchopulmonary dysplasia and perinatal characteristics predict 1 -year respiratory outcomes in newborns born at extremely low gestational age: a prospective cohort study. J Pediatr 2017; 187:89-97.e3.

19. Abman SH, Collaco JM, Shepherd EG, et al. Interdisciplinary care of children with severe bronchopulmonary dysplasia. J Pediatr 2017; 181:12-28.e1.

20. Higgins RD, Jobe AH, Koso-Thomas M, et al. Bronchopulmonary dysplasia: executive summary of a workshop. J Pediatr 2018; 197:300-308.

21. Jensen EA, Dysart K, Gantz MG, et al. The diagnosis of bronchopulmonary dysplasia in very preterm infants: an evidence-based approach. Am J Respir Crit Care Med 2019; 200:751-759.

22. Isayama T, Lee SK, Yang J, et al. Revisiting the definition of bronchopulmonary dysplasia: effect of changing panoply of respiratory support for preterm neonates. JAMA Pediatr 2017; 171:271-279.

23. Horbar JD, Edwards EM, Greenberg LT, et al. Variation in performance of neonatal intensive care units in the United States. JAMA Pediatr 2017; 171:e164396.

24. Ehrenkranz RA, Walsh MC, Vohr BR, et al. Validation of the National Institutes of Health consensus definition of bronchopulmonary dysplasia. Pediatrics 2005; 116:13531360 .

25. Morrow LA, Wagner BD, Ingram DA, et al. Antenatal determinants of bronchopulmonary dysplasia and late respiratory disease in preterm infants. Am J Respir Crit Care Med 2017; 196:364-374.

26. Taglauer E, Abman SH, Keller RL. Recent advances in antenatal factors predisposing to bronchopulmonary dysplasia. Semin Perinatol 2018; 42:413-424.

27. Mandell EW, Abman SH. Fetal vascular origins of bronchopulmonary dysplasia. J Pediatr 2017; 185:7-10 e1.

28. Hansen AR, Barnés CM, Folkman J, et al. Maternal preeclampsia predicts the development of bronchopulmonary dysplasia. J Pediatr 2010; 156:532-536.

29. Maynard SE, Min JY, Merchan J, et al. Excess placental soluble fms-like tyrosine kinase 1 (sFlt1) may contribute to endothelial dysfunction, hypertension, and proteinuria in preeclampsia. J Clin Invest 2003; 111:649-658.

30. Tang JR, Karumanchi SA, Seedorf G, et al. Excess soluble vascular endothelial growth factor receptor-1 in amniotic fluid impairs lung growth in rats: linking preeclampsia with bronchopulmonary dysplasia. Am J Physiol Lung Cell Mol Physiol 2012; 302:L36-L46.

31. Check J, Gotteiner N, Liu X, et al. Fetal growth restriction and pulmonary hypertension in premature infants with bronchopulmonary dysplasia. J Perinatol 2013; 33:553.

32. Mestan KK, Check J, Minturn L, et al. Placental pathologic changes of maternal vascular underperfusion in bronchopulmonary dysplasia and pulmonary hypertension. Placenta 2014; 35:570-574.

33. Hartling L, Liang Y, Lacaze-Masmonteil T. Chorioamnionitis as a risk factor for bronchopulmonary dysplasia: a systematic review and meta-analysis. Arch Dis Child Fetal Neonatal Ed 2012; 97:F8-F17.

34. Lal CV, Bhandari V, Ambalavanan N. Genomics, microbiomics, proteomics, and metabolomics in bronchopulmonary dysplasia. Semin Perinatol 2018; 42:425-431. 
35. Yu KH, Li J, Snyder M, et al. The genetic predisposition to bronchopulmonary dysplasia. Curr Opin Pediatr 2016; 28:318-323.

36. Parad RB, Winston AB, Kalish LA, et al. Role of genetic susceptibility in the development of bronchopulmonary dysplasia. J Pediatr 2018; 203:234-241.e2.

37. Bhandari V, Gruen JR, Jang KL, et al. Genetics of bronchopulmonary dysplasia: when things do not match up, it is only the beginning. J Pediatr 2019; 208:298299.

38. Pammi M, Lal CV, Wagner BD, et al. Airway microbiome and development of bronchopulmonary dysplasia in preterm infants: a systematic review. J Pediatr 2019; 204: 126-133.e2.

39. Jensen EA. Prevention of bronchopulmonary dysplasia: a summary of evidence-based strategies. Neoreviews 2019; 20:e189-e201.

40. Committee on Fetal and Newborn, American Academy of Pediatrics. Respiratory support in preterm infants at birth. Pediatrics 2014; 133:171-174.

41. Subramaniam P, Ho JJ, Davis PG. Prophylactic nasal continuous positive airway pressure for preventing morbidity and mortality in very preterm infants. Cochrane Database Syst Rev 2016; CD001243. DOI: 10.1002/1465 1858.CD001243.pub3.

42. Bahadue FL, Soll R. Early versus delayed selective surfactant treatment for neonatal respiratory distress syndrome. Cochrane Database Syst Rev 2012; 11:CD001456.

43. Klingenberg C, Wheeler KI, McCallion N, et al. Volumetargeted versus pressure-limited ventilation in neonates. Cochrane Database Syst Rev 2017; 10:CD003666.

44. Darlow BA, Graham P, Rojas-Reyes MX. Vitamin A supplementation to prevent mortality and short-and longterm morbidity in very low birth weight infants. Cochrane Database Syst Rev 2016; 2016:CD000501.

45. Dobson NR, Patel RM, Smith PB, et al. Trends in caffeine use and association between clinical outcomes and timing of therapy in very low birth weight infants. J Pediatr 2014; 164:992-998.e3.

46. Schmidt B, Roberts RS, Davis P, et al. Caffeine therapy for apnea of prematurity. N Engl J Med 2006; 354:21122121.

47. Onland W, De Jaegere A, Offringa M, et al. Systemic corticosteroid regimens for prevention of bronchopulmonary dysplasia in preterm infants. Cochrane Database Syst Rev 2017; 1:CD010941.

48. Shah SS, Ohlsson A, Halliday HL, et al. Inhaled versus systemic corticosteroids for preventing bronchopulmonary dysplasia in ventilated very low birth weight preterm neonates. Cochrane Database Syst Rev 2017; 10:CD002058.

49. Doyle LW, Cheong JL, Ehrenkranz RA, et al. Early $(<8$ days) systemic postnatal corticosteroids for prevention of bronchopulmonary dysplasia in preterm infants. Cochrane Database Syst Rev 2017; 10:CD001146.

50. Baud O, Maury L, Lebail F, et al. Effect of early low-dose hydrocortisone on survival without bronchopulmonary dysplasia in extremely preterm infants (PREMILOC): a double-blind, placebo-controlled, multicentre, randomised trial. Lancet 2016; 387:1827-1836.

51. Doyle LW, Cheong JL, Ehrenkranz RA, et al. Late ( $>7$ days) systemic postnatal corticosteroids for prevention of bronchopulmonary dysplasia in preterm infants. Cochrane Database Syst Rev 2017; 10:CD001145.

52. Marr BL, Mettelman BB, Bode MM, et al. Randomized trial of 42-day compared with 9-day courses of dexa- methasone for the treatment of evolving bronchopulmonary dysplasia in extremely preterm infants. J Pediatr 2019; 211 : 20-26.e1.

53. Aslam M, Baveja R, Liang OD, et al. Bone marrow stromal cells attenuate lung injury in a murine model of neonatal chronic lung disease. Am J Respir Crit Care Med 2009; 180:1122-1130.

54. van Haaften T, Byrne R, Bonnet S, et al. Airway delivery of mesenchymal stem cells prevents arrested alveolar growth in neonatal lung injury in rats. Am J Respir Crit Care Med 2009; 180:1131-1142.

55. Fung ME, Thebaud B. Stem cell-based therapy for neonatal lung disease: it is in the juice. Pediatr Res 2014; 75 : 2-7.

56. Augustine S, Avey MT, Harrison B, et al. Mesenchymal stromal cell therapy in bronchopulmonary dysplasia: systematic review and meta-analysis of preclinical studies. Stem Cells Transl Med 2017; 6:2079-2093.

57. Chang YS, Ahn SY, Yoo HS, et al. Mesenchymal stem cells for bronchopulmonary dysplasia: phase 1 dose-escalation clinical trial. J Pediatr 2014; 164:966972.e6.

58. Powell SB, Silvestri JM. Safety of intratracheal administration of human umbilical cord blood derived mesenchymal stromal cells in extremely low birth weight preterm infants. J Pediatr 2019; 210:209-213.e2.

59. Willis GR, Fernandez-Gonzalez A, Anastas J, et al. Mesenchymal stromal cell exosomes ameliorate experimental bronchopulmonary dysplasia and restore lung function through macrophage immunomodulation. Am J Respir Crit Care Med 2018; 197:104-116.

60. Lesage F, Thébaud B. Nanotherapies for micropreemies: stem cells and the secretome in bronchopulmonary dysplasia. Semin Perinatol 2018; 42:453-458.

61. Bolte C, Ustiyan V, Ren X, et al. Nanoparticle delivery of proangiogenic transcription factors into the neonatal circulation inhibits alveolar simplification caused by hyperoxia. Am J Respir Crit Care Med 2020; 202:100-111.

62. Ley D, Hallberg B, Hansen-Pupp I, et al. rhIGF1/rhIGFBP-3 in preterm infants: a phase 2 randomized controlled trial. J Pediatr 2019; 206:56-65.e8.

63. Collaco JM, McGrath-Morrow SA. Respiratory phenotypes for preterm infants, children, and adults: bronchopulmonary dysplasia and more. Ann Am Thorac Soc 2018; 15:530-538.

64. Wu KY, Jensen EA, White AM, et al. Characterization of disease phenotype in very preterm infants with severe bronchopulmonary dysplasia. Am J Respir Crit Care Med 2020; 201:1398-1406.

65. Hysinger EB, Friedman NL, Padula MA, et al. Tracheobronchomalacia is associated with increased morbidity in bronchopulmonary dysplasia. Ann Am Thorac Soc 2017; 14:1428-1435.

66. Hysinger EB, Panitch HB. Paediatric tracheomalacia. Paediatr Respir Rev 2016; 17:9-15.

67. Hysinger E, Friedman N, Jensen E, et al. Bronchoscopy in neonates with severe bronchopulmonary dysplasia in the NICU. J Perinatol 2019; 39:263-268.

68. Shepherd EG, Clouse BJ, Hasenstab KA, et al. Infant pulmonary function testing and phenotypes in severe bronchopulmonary dysplasia. Pediatrics 2018; 141:e20173350.

69. Baraldi E, Bonetto G, Zacchello F, et al. Low exhaled nitric oxide in school-age children with bronchopulmonary dysplasia and airflow limitation. Am J Respir Crit Care Med 2005; 171:68-72. 
70. Vollsaeter M, Clemm HH, Satrell E, et al. Adult respiratory outcomes of extreme preterm birth. A regional cohort study. Ann Am Thorac Soc 2015; 12:313-322.

71. Landry JS, Tremblay GM, Li PZ, et al. Lung function and bronchial hyperresponsiveness in adults born prematurely. A cohort study. Ann Am Thorac Soc 2016; 13:17-24.

72. Thunqvist $P$, Tufvesson E, Bjermer L, et al. Lung function after extremely preterm birth-A population-based cohort study (EXPRESS). Pediatr Pulmonol 2018; 53:64-72.

73. Doyle LW, Carse E, Adams AM, et al. Ventilation in extremely preterm infants and respiratory function at 8 years. N Engl J Med 2017; 377:329-337.

74. Abman SH. Bronchopulmonary dysplasia: "A Vascular Hypothesis." Am J Respir Crit Care Med 2001; 164: 1755-1756.

75. Galambos C, Sims-Lucas S, Abman SH. Histologic evidence of intrapulmonary anastomoses by three-dimensional reconstruction in severe bronchopulmonary dysplasia. Ann Am Thorac Soc 2013; 10:474-481.

76. Chang DV, Assaf SJ, Tiller CJ, et al. Membrane and capillary components of lung diffusion in infants with bronchopulmonary dysplasia. Am J Respir Crit Care Med 2016; 193:767-771.

77. Narayanan M, Beardsmore CS, Owers-Bradley J, et al. Catch-up alveolarization in ex-preterm children: evidence from (3)He magnetic resonance. Am J Respir Crit Care Med 2013; 187:1104-1109.

78. Ochiai M, Hikino S, Yabuuchi H, et al. A new scoring system for computed tomography of the chest for assessing the clinical status of bronchopulmonary dysplasia. J Pediatr 2008; 152:90-95, 95.e1-e3.

79. Spielberg DR, Walkup LL, Stein JM, et al. Quantitative CT scans of lung parenchymal pathology in premature infants ages 0-6 years. Pediatr Pulmonol 2018; 53:316323.

80. Higano NS, Spielberg DR, Fleck RJ, et al. Neonatal pulmonary magnetic resonance imaging of bronchopulmonary dysplasia predicts short-term clinical outcomes. Am J Respir Crit Care Med 2018; 198:1302-1311.

81. Khemani E, McElhinney DB, Rhein L, et al. Pulmonary artery hypertension in formerly premature infants with bronchopulmonary dysplasia: clinical features and outcomes in the surfactant era. Pediatrics 2007; 120:1260 1269.

82. An HS, Bae EJ, Kim GB, et al. Pulmonary hypertension in preterm infants with bronchopulmonary dysplasia. Korean Circ J 2010; 40:131-136.

83. Abman SH, Grenolds A, Mourani P. Pulmonary vascular disease in bronchopulmonary dysplasia. Adv Pulm Hypertens 2016; 15:92-99.

84. Krishnan U, Feinstein JA, Adatia I, et al. Evaluation and management of pulmonary hypertension in children with bronchopulmonary dysplasia. J Pediatr 2017; 188:2434.e1.

85. Mourani PM, Abman SH. Pulmonary hypertension and vascular abnormalities in bronchopulmonary dysplasia. Clin Perinatol 2015; 42:839-855.

86. Mourani PM, Sontag MK, Younoszai A, et al. Early pulmonary vascular disease in preterm infants at risk for bronchopulmonary dysplasia. Am J Respir Crit Care Med 2015; 191:87-95.

87. Cuna A, Kandasamy J, Sims B. B-type natriuretic peptide and mortality in extremely low birth weight infants with pulmonary hypertension: a retrospective cohort analysis. BMC Pediatrics 2014; 14:68.
88. Berkelhamer SK, Mestan KK, Steinhorn R. An update on the diagnosis and management of bronchopulmonary dysplasia (BPD)-associated pulmonary hypertension. Semin Perinatol 2018; 42:432-443.

89. Abman SH NL. Management of the infant with severe bronchopulmonary dysplasia. In: Bancalari E, ed. The newborn lung: neonatology questions and controversies. Philadelphia (PA): Elsevier Saunders, 2012, pp. 407-425.

90. Baker CD. Long-term ventilation for children with chronic lung disease of infancy. Curr Opin Pediatr 2019; 31:357-366.

91. Napolitano N, Jalal K, McDonough JM, et al. Identifying and treating intrinsic PEEP in infants with severe bronchopulmonary dysplasia. Pediatr Pulmonol 2019; 54: 1045-1051.

92. Cristea AI, Baker CD. Ventilator weaning and tracheostomy decannulation in children: more than one way. Pediatr Pulmonol 2016; 51:773-774.

93. Cristea AI, Carroll AE, Davis SD, et al. Outcomes of children with severe bronchopulmonary dysplasia who were ventilator dependent at home. Pediatrics 2013; 132: e727-e734.

94. DeMauro SB, D'Agostino JA, Bann C, et al. Developmental outcomes of very preterm infants with tracheostomies. J Pediatr 2014; 164:1303-1310.e2.

95. Overman AE, Liu M, Kurachek SC, et al. Tracheostomy for infants requiring prolonged mechanical ventilation: 10 years' experience. Pediatrics 2013; 131:e1491-e1496.

96. Zhang H, Luo J, Shepard S, et al. Improved growth and infant participation in developmental activities after tracheostomy placement in infants with severe bronchopulmonary dysplasia. Pediatrics 2018; 141:530.

97. Baker CD, Martin S, Thrasher J, et al. A standardized discharge process decreases length of stay for ventilatordependent children. Pediatrics 2016; 137:e20150637.

98. Gien J, Kinsella J, Thrasher J, et al. Retrospective analysis of an interdisciplinary ventilator care program intervention on survival of infants with ventilator-dependent bronchopulmonary dysplasia. Am J Perinatol 2017; 34: 155-163.

99. Moyer-Mileur LJ, Nielson DW, Pfeffer KD, et al. Eliminating sleep-associated hypoxemia improves growth in infants with bronchopulmonary dysplasia. Pediatrics 1996; 98:779-783.

100. Harris M-A, Sullivan C. Sleep pattern and supplementary oxygen requirements in infants with chronic neonatal lung disease. Lancet 1995; 345:831-832.

101. Mourani PM, Ivy DD, Gao D, et al. Pulmonary vascular effects of inhaled nitric oxide and oxygen tension in bronchopulmonary dysplasia. Am J Respir Crit Care Med 2004; 170:1006-1013.

102. Palm K, Simoneau T, Sawicki G, et al. Assessment of current strategies for weaning premature infants from supplemental oxygen in the outpatient setting. Adv Neonatal Care 2011; 11:349-356.

103. Hayes Jr. D, Wilson KC, Krivchenia K, et al. Home oxygen therapy for children. An Official American Thoracic Society Clinical Practice Guideline. Am J Respir Crit Care Med 2019; 199:e5-e23.

104. Yeh J, McGrath-Morrow SA, Collaco JM. Oxygen weaning after hospital discharge in children with bronchopulmonary dysplasia. Pediatr Pulmonol 2016; 51:12061211.

105. Duijts L, van Meel ER, Moschino L, et al. European Respiratory Society guideline on long-term management 
of children with bronchopulmonary dysplasia. Eur Respir J 2020; 55:1900788.

106. DeMauro SB, Jensen EA, Bann CM, et al. Home oxygen and 2-year outcomes of preterm infants with bronchopulmonary dysplasia. Pediatrics 2019; 143:e20182956.

107. Ehrenkranz RA, Dusick AM, Vohr BR, et al. Growth in the neonatal intensive care unit influences neurodevelopmental and growth outcomes of extremely low birth weight infants. Pediatrics 2006; 117:1253-1261.

108. Poindexter BB, Martin CR. Impact of nutrition on bronchopulmonary dysplasia. Clin Perinatol 2015; 42: 797-806.

109. Barrington KJ, Fortin-Pellerin E, Pennaforte T. Fluid restriction for treatment of preterm infants with chronic lung disease. Cochrane Database Syst Rev 2017; 2:CD005389.

110. Warren MG, Do B, Das A, et al. Gastrostomy tube feeding in extremely low birthweight infants: frequency, associated comorbidities, and long-term outcomes. J Pediatr 2019; 214:41-46.e5.

111. Duncan DR, Mitchell PD, Larson K, et al. Presenting signs and symptoms do not predict aspiration risk in children. J Pediatr 2018; 201:141-146.

112. Eichenwald EC, Committee on Fetus and Newborn. Diagnosis and management of gastroesophageal reflux in preterm infants. Pediatrics 2018; 142:e20181061.

113. Wallenstein MB, Brooks C, Kline TA, et al. Early transpyloric vs gastric feeding in preterm infants: a retrospective cohort study. J Perinatol 2019; 39:837-841.

114. Jensen EA, Zhang H, Feng R, et al. Individualising care in severe bronchopulmonary dysplasia: a series of N-of-1 trials comparing transpyloric and gastric feeding. Arch Dis Child Fetal Neonatal Ed 2020; 105:399-404.

115. Jensen EA, Munson DA, Zhang H, et al. Antigastroesophageal reflux surgery in infants with severe bronchopulmonary dysplasia. Pediatr Pulmonol 2015; 50:584-587.

116. Guaman MC, Gien J, Baker CD, et al. Point prevalence, clinical characteristics, and treatment variation for infants with severe bronchopulmonary dysplasia. Am J Perinatol 2015; 32:960-967.

117. Kao LC, Warburton D, Sargent CW, et al. Furosemide acutely decreases airways resistance in chronic bronchopulmonary dysplasia. J Pediatr 1983; 103:624-629.

118. Stewart A, Brion LP. Intravenous or enteral loop diuretics for preterm infants with (or developing) chronic lung disease. Cochrane Database Syst Rev 2011; 2011:CD001453.

119. Stewart A, Brion LP, Ambrosio-Perez I. Diuretics acting on the distal renal tubule for preterm infants with (or developing) chronic lung disease. Cochrane Database Syst Rev 2011; 2011:CD001817.

120. Blaisdell CJ, Troendle J, Zajicek A, et al. Acute responses to diuretic therapy in extremely low gestational age newborns: results from the prematurity and respiratory outcomes program cohort study. J Pediatr 2018; 197:42-47.e1.

121. Slaughter JL, Stenger MR, Reagan PB. Variation in the use of diuretic therapy for infants with bronchopulmonary dysplasia. Pediatrics 2013; 131:716-723.

122. Laughon MM, Chantala K, Aliaga S, et al. Diuretic exposure in premature infants from 1997 to 2011. Am J Perinatol 2015; 32:49-56.

123. Slaughter JL, Stenger MR, Reagan PB, et al. Inhaled bronchodilator use for infants with bronchopulmonary dysplasia. J Perinatol 2015; 35:61-66.

124. Ng G, da Silva O, Ohlsson A. Bronchodilators for the prevention and treatment of chronic lung disease in pre- term infants. Cochrane Database Syst Rev 2016; 12: CD003214.

125. Bhandari A, Panitch H. An update on the post-NICU discharge management of bronchopulmonary dysplasia. Semin Perinatol 2018; 42:471-477.

126. Logan JW, Lynch SK, Curtiss J, et al. Clinical phenotypes and management concepts for severe, established bronchopulmonary dysplasia. Paediatr Respir Rev 2019; 31:58-63.

127. Nelin LD, Logan JW. The use of inhaled corticosteroids in chronically ventilated preterm infants. Semin Fetal Neonatal Med 2017; 22:296-301.

128. Diseases CoI. Updated guidance for palivizumab prophylaxis among infants and young children at increased risk of hospitalization for respiratory syncytial virus infection. Pediatrics 2014; 134:e620-e638.

129. Mac S, Sumner A, Duchesne-Belanger S, et al. Costeffectiveness of palivizumab for respiratory syncytial virus: a systematic review. Pediatrics 2019; 143:e20184064.

130. Banks BA, Seri I, Ischiropoulos H, et al. Changes in oxygenation with inhaled nitric oxide in severe bronchopulmonary dysplasia. Pediatrics 1999; 103:610-618.

131. Thompson EJ, Perez K, Hornik CP, et al. Sildenafil exposure in the neonatal intensive care unit. Am J Perinatol 2019; 36:262-267.

132. Mourani PM, Sontag MK, Ivy DD, et al. Effects of longterm sildenafil treatment for pulmonary hypertension in infants with chronic lung disease. J Pediatr 2009; 154: 379-384, 384.e1-e2.

133. Islam JY, Keller RL, Aschner JL, et al. Understanding the short- and long-term respiratory outcomes of prematurity and bronchopulmonary dysplasia. Am J Respir Crit Care Med 2015; 192:134-156.

134. Smith VC, Zupancic JA, McCormick MC, et al. Rehospitalization in the first year of life among infants with bronchopulmonary dysplasia. J Pediatr 2004; 144:799803.

135. Simpson SJ, Logie KM, O'Dea CA, et al. Altered lung structure and function in mid-childhood survivors of very preterm birth. Thorax 2017; 72:702-711.

136. Sillers L, Alexiou S, Jensen EA. Lifelong pulmonary sequelae of bronchopulmonary dysplasia. Curr Opin Pediatr 2020; 32:252-260.

137. Bui DS, Lodge CJ, Burgess JA, et al. Childhood predictors of lung function trajectories and future COPD risk: a prospective cohort study from the first to the sixth decade of life. Lancet Respir Med 2018; 6:535-544.

138. Thebaud B, Goss KN, Laughon $\mathrm{M}$, et al. Bronchopulmonary dysplasia. Nat Rev Dis Primers 2019; 5:78.

Address correspondence to: Michael C. Tracy, MD Center for Excellence in Pulmonary Biology Division of Pediatric Pulmonary, Asthma and Sleep Medicine

Department of Pediatrics Stanford University School of Medicine 770 Welch Road Stanford, CA 94304

USA

E-mail: mtracy@stanford.edu

Received for publication May 12, 2020; accepted after revision August 14, 2020. 